\title{
APPLICATION OF MARKOWITZ PORTFOLIO OPTIMIZATION ON BULGARIAN STOCK MARKET FROM 2013 TO 2016
}

\author{
M. Ivanova ${ }^{1}$, L. Dospatliev ${ }^{2}$ \\ ${ }^{1}$ Department of Informatics and Mathematics \\ Faculty of Economics \\ Trakia University \\ Studentski Grad, Stara Zagora, 6000, BULGARIA \\ ${ }^{2}$ Department of Pharmacology \\ Animal Physiology and Physiological Chemistry \\ Faculty of Veterinary Medicine \\ Trakia University \\ Studentski Grad, Stara Zagora, 6000, BULGARIA
}

\begin{abstract}
Investors of any time and of any investment area are faced with the conflicting objective of minimizing risks and simultaneously maximizing returns. Considering the tradeoffs between risk and return, Harry Markowitz, an American financial economist, proposed the so-called optimal portfolio theory in 1952. The aim of this paper is to provide a practical study of Markowitz model on the Bulgarian stock market from 2013 to 2016. The significance of this study arises from the fact that although Markowitz model has been widely used by investors worldwide, its application on Bulgarian stock market is still relatively limited. From the data inputs which are weekly closing prices of 50 stocks traded on Bulgarian Stock Exchange between January 2013 and December 2016, efficient frontiers in addition to optimal portfolios are determined on the basis of Markowitz theory. As a result, Bulgarian investors can select their own optimal portfolio that maximizes portfolio rate of return with respect to their risk preference.
\end{abstract}

AMS Subject Classification: 62-07, 49M37, 90C30, 34K60, 91B30

$\begin{array}{lrc}\text { Received: } & 2017-06-14 & \text { C } 2017 \text { Academic Publications, Ltd. } \\ \text { Revised: } & 2017-11-15 & \text { url: www.acadpubl.eu } \\ \text { Published: } & \text { December } 23,2017 & \end{array}$


Key Words: portfolio risk, portfolio return, Sharpe's measure, portfolio efficient frontier, Optimal Markowitz portfolio

\section{Introduction}

The portfolio optimization plays an important role in determining the portfolio strategies for investors. What investors hope to achieve through a portfolio optimization is to maximize portfolio return and minimize portfolio risk. Since the return changes based on risk investors have to balance the contradiction between risk and return for their investment. There is therefore no single optimized portfolio to satisfy all investors. The optimal portfolio is determined by the preferences of the investor's risk and return (see [22], [10], [9]).

Modern portfolio theory was developed by American financial economist Harry Markowitz in 1952 in the article "Portfolio Selection" (see [13]). Markowitz developed his ideas for portfolio optimization in the book "Portfolio Selection: Efficient Diversification of Investments" in 1959 (see [12]).

Although there are many extensions and developments made on the model of Markowitz (see [24], [23], [26], [27], [17], [7], [6], [29], [11], [18], [19], [8], [20], [28], [15], [16]), this model is still widely used.

The aim of this article is from the data inputs which are weekly closing prices of 50 stocks traded on Bulgarian Stock Exchange between January 2013 and December 2016, to determine on the basis of Markowitz theory efficient frontiers in addition to three optimal portfolios (Minimum risk portfolio, Maximum portfolio return for a given level of risk, and Maximum Sharpe ratio portfolio). As a result, Bulgarian investors can select their own optimal portfolio that maximizes portfolio rate of return with respect to their risk preference.

\section{Markowitz Portfolio Theory}

\subsection{Parameters of Markowitz Model Based on Historical Data of Stock Prices}

\subsubsection{Rate of Return}

Rate of return is the ratio of the return of money gain or loss from the investment that the investor does. The money invested may be referred to as an asset, capital, principal, or the cost basis of the investment. The rate of return 
expected by an investor can be calculated from the data that already exist and future investor's expectations. The result of rate of return is usually expressed as a percentage.

The arithmetic rate of return $r_{t}$ on investments in asset between time $t$ and $t-1$ is calculated by the formula (see [1]):

$$
r_{t}=\frac{P_{t}-P_{t-1}}{P_{t-1}}
$$

where $P_{t}$ is the price of the stock at time $t$ and we assume for now that this stock pays dividends and let $P_{t-1}$ be the price at time $t-1$.

\subsubsection{Expected Return}

Let us have $n$ number of assets. Then the expected return $\mu_{i}$ on asset $i, i=$ $1, \ldots, n$ is calculated by (see [2]):

$$
\mu_{i}=E\left(r^{i}\right)=\frac{\sum_{t=1}^{m} r_{t}^{i}}{m}
$$

where $r_{t}^{i}$ is the return on asset $i$ between periods $t-1$ and $t, t=1, \ldots, m$ and $m$ is the number of periods, whose return we have calculated.

\subsubsection{Variance and Standard Deviation}

The variance on asset $i$ is calculated using the following formula (see [2]):

$$
\sigma_{i}^{2}=\operatorname{Var}\left(r^{i}\right)=\frac{\sum_{t=1}^{m}\left(r_{t}^{i}-\mu_{i}\right)^{2}}{m-1} .
$$

The standard deviation is often used by the investors to measure the risk of their assets. In [4] the standard deviation is defined as the most common statistical indicator of an asset's risk which measures the dispersion around the expected value. The higher the standard deviation means that it has greater risk and vice versa. The formula of standard deviation is as follows

$$
\sigma_{i}=\sqrt{\sigma_{i}^{2}}=\sqrt{\frac{\sum_{t=1}^{m}\left(r_{t}^{i}-\mu_{i}\right)^{2}}{m-1}} .
$$

\subsubsection{Covariance}

When we work with assets, dimensions of risk are organized in the return covariance matrix, which is denoted by $\Omega_{n \times n}$. This matrix contains variances in 
its main diagonal and covariances between all pairs of assets other items, i.e.

$$
\Omega_{n \times n}=\left(\begin{array}{cccc}
\sigma_{1}^{2} & \sigma_{12} & \ldots & \sigma_{1 n} \\
\sigma_{21} & \sigma_{2}^{2} & \ldots & \sigma_{2 n} \\
\vdots & \vdots & \ddots & \vdots \\
\sigma_{n 1} & \sigma_{n 2} & \ldots & \sigma_{n}^{2}
\end{array}\right)
$$

where

$$
\sigma_{i j}=\operatorname{Cov}\left(r^{i}, r^{j}\right)=\frac{\sum_{t=1}^{m}\left(r_{t}^{i}-\mu_{i}\right)\left(r_{t}^{j}-\mu_{j}\right)}{m} .
$$

\subsection{Markowitz Model}

Until the publication of the modern portfolio theory by Harry Markowitz in 1952 in the article "Portfolio Selection" (see [13]), investors were focused on assessing the risk and return of individual securities when constructing portfolios. Investment decisions were based on identifying securities with the highest return and at less risk, then they were included in the investment portfolio. Markowitz offers another approach called diversification, where construction of the portfolio is made after evaluation of the overall portfolio risk, i.e. selectable portfolio in aggregate, not to construct a portfolio of distinct, preselected securities. Thus the emphasis is on the relationships between the characteristics of the assets rather than on the actual characteristics.

In 1990, Harry Markowitz, together with Morton Miller and William Sharpe, was awarded the Nobel Prize in Economics for his work on portfolio theory. The basic assumption in it is that the return securities for a period of time are random variables and therefore mathematical expectation and standard deviation can be calculated as the standard deviation is considered a measure of investment risk. The expected return on the portfolio $E\left(r_{P}\right)$ is a linear combination of the expected return on assets included in it, such factors are the relative shares of the assets in the portfolio. Investment risk is measured by the standard deviation $\sigma_{P}$, which depends on nonlinear standard deviations and covariances of return on individual assets.

The idea of diversification of Markowitz is subject to the fact that with increasing number of assets in the portfolio, the corresponding number of covariances becomes significantly larger than the number of assets and therefore the risk of the portfolio will depend to a greater degree on covariance between assets rather than on risk of individual assets. The apparent form of parametric optimization of Markowitz model has the following mathematical representation 
$($ see $[14])$ :

$$
\mid \begin{aligned}
& \max E\left(r_{P}\right)=\max \sum_{i=1}^{n} \omega_{i} \mu_{i} \\
& \min \sigma_{P}=\min \sqrt{\sum_{i=1}^{n} \sum_{j=1}^{n} \omega_{i} \omega_{j} \sigma_{i j}} \\
& 0 \leq \omega_{i} \leq 1, \quad i=1, \ldots, n \\
& \sum_{i=1}^{n} \omega_{i}=1
\end{aligned}
$$

where $\omega_{i}$ is a percentage of capital that will be invested in asset $i ; r^{i}$ is the return on asset $i ; \mu_{i}$ the expected return on asset $i ; \mu_{i j}$ is the covariance between the return on assets $i$ and $j ; E\left(r_{P}\right)$ is the expected return of the portfolio; $\sigma_{P}$ is the risk of the portfolio.

This model is both common enough for most practical situations and simple enough for theoretical analysis and numerical solutions. This model bears the name of its creator Markowitz model, but also occurs as Mean-Variance model.

The Markowitz model is based on several assumptions concerning the behavior of investors and financial markets (see [3]):

- A probability distribution of possible returns over some holding period can be estimated by investors.

- Investors have single-period utility functions in which they maximize utility within the framework of diminishing marginal utility of wealth.

- Variability about the possible values of return is used by investors to measure risk.

- Investors care only about the means and variance of the returns of their portfolios over a particular period.

- Expected return and risk as used by investors are measured by the first two moments of the probability distribution of returns - expected value and variance.

- Return is desirable; risk is to be avoided.

- Financial markets are frictionless.

- There is no transaction cost or taxes.

\subsection{Sharpe's Measure}

Sharpe's measure is also known as Sharpe ratio or reward-to-volatility ratio. According to [25] and [21], Sharpe's measure is a measure of portfolio performance that gives the risk premium per unit of total risk, which is measured 
by the portfolio's standard deviation of return. The risk premium on a portfolio itself is the total portfolio return minus the risk-free rate. In other words, Sharpe's measure divides average portfolio excess return by the standard deviation of returns on the same time period. Sharpe's measure can be expressed in the following formula

$$
S_{P}=\frac{E\left(r_{P}-r_{f}\right)}{\sigma_{P}},
$$

where $r_{f}$ is the return on the risk free asset.

\subsection{Portfolio Efficient Frontier}

Every possible asset combination can be plotted in risk-return space, and the collection of all such possible portfolios defines a region in this space. The line along the upper edge of this region is known as the efficient frontier sometimes called the "Markowitz bullet". Combinations along this line represent portfolios (explicitly excluding the risk-free alternative) for which there is lowest risk for a given level of return. Conversely, for a given amount of risk, the portfolio lying on the efficient frontier represents the combination offering the best possible return. Mathematically the efficient frontier is the intersection of the set of portfolios with minimum risk and the set of portfolios with maximum return (see [3], [5]).

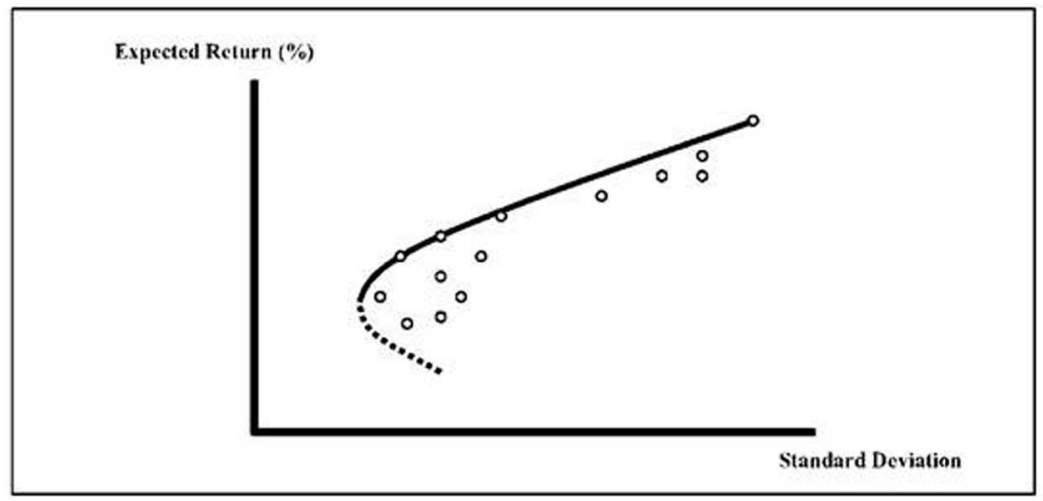

Figure 1: Efficient frontier

Figure 1 shows investors the entire investment opportunity set, which is the set of all attainable combinations of risk and return offered by portfolios formed by assets in differing proportions (see [3]). The combination of the 
specific risky assets in the portfolio plotted on the efficient frontier represents the lowest risk possible for the portfolio for a desired level of expected return, or the best possible expected return for an acceptable risk level.

\section{Analysis and Discussion of Result}

\subsection{Selecting Stocks Exchanged on the Official Stock Market}

A great period of time, at least 30 years, is required to make useful and realistic forecast of the risk and expected return of the stocks. Unfortunately, the Bulgarian capital market has not such a long history. The data for this research are historical stock prices of 50 largest listed companies exchanging on the Bulgarian Stock Exchange. Specifically, weekly closing prices of stocks are tracked down throughout the period from January 2013 and December 2016.

As of December 2016, there are 516 companies listed on the Bulgarian Stock Exchange. Fifty of them were chosen for the study based on both criteria as follows:

- the sequence of chosen codes is from the largest market capital to the $50^{\text {th }}$ largest market capital on the stock market;

- the listed companies have minimum 4 years of listing on the market, at least from January 2013 to December 2016 guaranteed by the completeness of the whole database.

The list of 50 companies is: Zarneni Hrani Bulgaria (ZHBG), Chimimport AD (CHIM), Biovet (BIOV), Holding Varna (HVAR), Neochim PLC (NEOH), Sopharma AD (SFARM), First Investment Bank AD (FIB), Oil and Gas Exploration and Production PLC (GAZ), Monbat PLC (MONBAT), ELHIMISKRA JSC (ELHIM), Trace Group Hold PLC (TRACE), Eurohold Bulgaria AD (EUBG), Enemona (E4AP), Toplivo JSC (TOPL), Alcomet AD (ALUM), Stara Planina Hold PLC (CENHL), Petrol AD (PET), Bulgarian Stock Exchange - Sofia (BSO), Bulland Investmemts (LAND), Fazerles AD (FZLES), FairPlay Properties REIT (FPP), Speedy JSC (0SP), TK-HOLD PLC-SOFIA (TCH), Hydraulic Elements \& Systems PLC (HES), Albena JSC (ALB), Agria Group Holding JSC (AGR), Advance Terrafund (ATERA), M + S Hydraulic PLC (MCH), Bulgarian Real Estate Fund REIT (BREF), DOVERIE - United Holding PLC (DOVUHL), CEZ Electro Bulgaria AD (3CZ), Industrial Holding Bulgaria PLC (IHLBL), Holding Nov Vek AD (HNVEK), Momina Krepost PLC (MOMKR), Energoremont Holding JSC (ERH), Odessos Shiprepair Yard 
SA (ODES), Bulgarian River Shipping JSC (BRP), Technologies and Innovations Corporation PLC (KRS), Zaharni zavodi AD (ZAHZA), Lavena AD - Shumen (LAVEN), Aroma PLC (AROMA), Bulgarian Rose PLC (ROZA), Sparky Eltos AD (ELTOS), Todorov AD (TODOROF), Yuri Gagarin PLC (GAGBT), ELANA Agrocredit (0EA), Euroins Insurance PLC (EURINS), Energetics and Energy Savings Fund - FEEI SPV-Sofia (FEEI), ERG Capital - 3 ADSIP (ERGC3), Unipack AD (UPAC).

\subsection{Risk and Return of Individual Stock}

By use of (1) and (2) we can compute the average weekly return for each of the 50 assets. There are 47 out of 50 sample stocks yielding positive return within the study period from January 2013 to December 2016. The remaining 6\% has poor performance with negative rate of return.

Top ten stocks earning the highest rate of return are pointed out in the Table 1. As can be seen from the table, Technologies and Innovations Corporation PLC (KRS) leads the market in terms of average return (6,57\% weekly), closely followed by the stock of TODOROF - Todorov AD ( $5,73 \%$ weekly).

In contrast to good performers, Table 1 also identifies other 10 stocks which have the smallest return in the sample. Three of them producing negative return, PET - Petrol AD is the worst with weekly rate of return at - 0,42\%. EUBG and ATERA also stand in the bottom line, making loss at weekly rate of $-0,12 \%,-0,01 \%$, respectively.

Table 1: Top 10 highest return and top 10 smallest return.

\begin{tabular}{lc|lc}
\hline \multicolumn{2}{c}{ Top 10 highest return } & \multicolumn{2}{|c}{ Top 10 smallest return } \\
Name & Return, \% & Name & Return, \% \\
\hline KRS & 6,57 & PET & $-0,42$ \\
TODOROF & 5,73 & EUBG & $-0,12$ \\
FEEI & 4,54 & ATERA & $-0,01$ \\
MOMKR & 2,36 & BSO & 0,11 \\
AROMA & 1,95 & EURINS & 0,16 \\
HNVEK & 1,77 & BRP & 0,16 \\
ROZA & 1,20 & TCH & 0,18 \\
BREF & 1,15 & OEA & 0,19 \\
ZAHZA & 1,13 & 3CZ & 0,20 \\
UPAC & 1,02 & SFARM & 0,22 \\
\hline
\end{tabular}


By (4) we can easily get the risk for each of the 50 assets. As can be seen in Table 2, the smallest risk recorded belongs to the stock 0EA - ELANA Agrocredit at 2,33\% per week, while the highest risk recorded is to the stock FEEI - Energetics and Energy Savings Fund at 56,93\% per week. These results show that the risk of each stock varies greatly per weekly basis which indicates the high variability of investment.

Table 2: Top 10 lowest risk and Top 10 highest risk.

\begin{tabular}{lc|lc}
\multicolumn{2}{c}{ Top 10 highest risk } & \multicolumn{2}{c}{ Top 10 smallest risk } \\
Name & Risk, \% & Name & Risk, \% \\
\hline FEEI & 56,93 & OEA & 2,33 \\
TODOROF & 45,63 & ATERA & 2,38 \\
KRS & 42,84 & MONBAT & 2,71 \\
MOMKR & 26,91 & OSP & 2,72 \\
E4AP & 26,28 & SFARM & 2,77 \\
AROMA & 25,01 & CENHL & 3,43 \\
HNVEK & 14,75 & MCH & 3,47 \\
BREF & 13,84 & 3CZ & 3,56 \\
UPAC & 13,61 & ALB & 4,08 \\
ZAHZA & 13,39 & EUBG & 4,17 \\
\hline
\end{tabular}

\subsection{Minimum Risk Portfolio}

Precise weights for component assets in the minimum risk portfolio were obtained by using the definition (6) of Markowitz model and equations (3), (4) and (5). They are shown in Table 3.

In this portfolio, 40 assets in the sample of 50 stocks remained with different weight allocation. The rest 10 out of 50 stocks are excluded. It is noteworthy that $0 \mathrm{EA}$ is the impressive stock receiving the largest weight allocation of $15,14 \%$.

The minimum risk portfolio has its mean return of $0,38 \%$ with the level of risk equivalent to $0,83 \%$ risk per week. The Sharpe ratio for this portfolio is 0,27 with an amount of risk-free assets equal to $0,16 \%$.

As can be seen in Table 2, the one with the lowest risk is the 0EA stock (the weekly risk equals $2,33 \%$ ), while its mean return takes a tiny percentage of $0,19 \%$ per week. 
Table 3: Minimum risk portfolio.

\begin{tabular}{llllll}
\hline Name & $\omega_{i}, \%$ & Name & $\omega_{i}, \%$ & Name & $\omega_{i}, \%$ \\
\hline ZHBG & 0,38 & FZLES & 4,05 & ZAHZA & 0,78 \\
CHIM & 0,09 & FPP & 0,86 & LAVEN & 0,25 \\
BIOV & 1,71 & 0SP & 13,09 & AROMA & 0,19 \\
HVAR & 1,23 & TCH & 0,46 & ROZA & 0,49 \\
NEOH & 0,37 & HES & 3,36 & ELTOS & 0,60 \\
SFARM & 8,01 & ALB & 3,66 & TODOROF & 0,03 \\
GAZ & 1,61 & AGR & 4,50 & GAGBT & 2,36 \\
MONBAT & 3,32 & MCH & 3,55 & 0EA & 15,14 \\
ELHIM & 2,51 & BREF & 0,62 & EURINS & 0,54 \\
TRACE & 0,36 & DOVUHL & 1,72 & FEEI & 0,15 \\
E4AP & 0,14 & 3 CZ & 6,70 & ERGC3 & 0,20 \\
ALUM & 3,85 & ERH & 0,04 & UPAC & 0,40 \\
CENHL & 2,69 & ODES & 3,81 & & \\
LAND & 4,20 & BRP & 1,96 & \\
\hline Portfolio return & \multicolumn{5}{c}{$0,38 \%$} \\
Portfolio risk & \multicolumn{5}{c}{$0,83 \%$} \\
Sharpe ratio
\end{tabular}

\subsection{Efficient Frontier of Minimizing Risk Portfolio}

The Efficient frontier illustrating the set of efficient portfolios with the lowest risk for any target rate of return is shown in Figure 2. Given the same level of return, there are no other portfolios offering lower risk than the ones located on this efficient frontier.

Once the efficient frontier is constructed, the task of particular investors is to choose their own applicable portfolio from points on the graph depending on their distinguished risk preference. Investors who have low risk tolerance are likely to select portfolios with risk and return combination located on the left of the frontier. In contrast, those who are willing to accept high risk to earn more return are likely to be interested in portfolios located on the right of the frontier. 


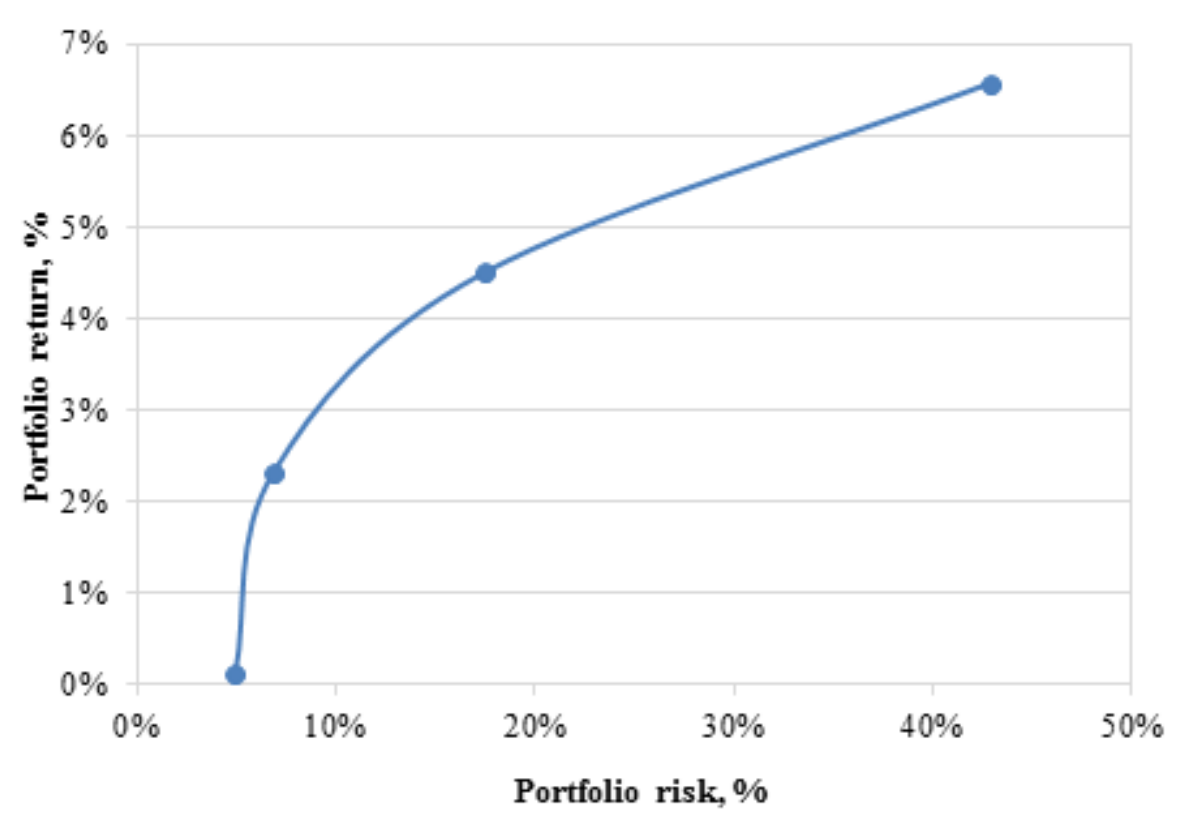

Figure 2: Efficient frontier minimizing risk portfolio

\subsection{Maximum Portfolio Return for a Given Level of Risk}

According to the results in Table 2, the lowest weekly risk offered by individual stocks is $2,33 \%$ (0EA's). From this point, we set a target to increase return of the efficient portfolio as high as possible but still stick to the low risk. The maximum return portfolio at a level of risk less than or equal to $2,33 \%$ is determined by (6), (3), (4) and (5).

Precise weights for component stocks in the maximum return portfolio are shown in Table 4.

In this portfolio, only 27 of 50 stocks remained with different weight allocation. The rest 23 stocks are excluded. The majority of weight allocation goes to six stocks, namely, AGR, CENHL, HES, MCH, ALUM and 0SP. These six stocks account for more than $50 \%$ allocation of the total portfolio.

The maximum return portfolio has its mean return of $1,09 \%$ with level of risk $2,33 \%$ per week. In this portfolio the Sharpe ratio is 0,40 with an amount of risk-free assets equal to $0,16 \%$. 
Table 4: Optimal portfolio based on 2,33\% weekly rate of risk.

\begin{tabular}{llllll}
\hline Name & $\omega_{i}, \%$ & Name & $\omega_{i}, \%$ & Name & $\omega_{i}, \%$ \\
\hline BIOV & 1,14 & HES & 7,81 & ZAHZA & 1,89 \\
HVAR & 3,52 & AGR & 11,96 & LAVEN & 2,20 \\
ELHIM & 0,95 & MCH & 7,39 & AROMA & 1,70 \\
E4AP & 0,82 & BREF & 3,67 & ROZA & 5,71 \\
ALUM & 7,17 & HNVEK & 4,90 & ELTOS & 1,09 \\
CENHL & 11,11 & MOMKR & 1,46 & TODOROF & 2,12 \\
FZLES & 0,87 & ERH & 1,44 & FEEI & 1,49 \\
FPP & 3,56 & ODES & 2,89 & ERGC3 & 1,46 \\
0SP & 6,96 & KRS & 2,72 & UPAC & 2,00 \\
\hline Portfolio return & & \multicolumn{5}{c}{$1,09 \%$} & \\
Portfolio risk & \multicolumn{5}{c}{$2,33 \%$} \\
Sharpe ratio & \multicolumn{5}{c}{0,40} \\
\hline
\end{tabular}

As can be seen from Table 1, there is no doubt that Markowitz diversification does improve performance of the investment. Given the same level of risk $(2,33 \%)$ the portfolio's return constructed on the basis of Markowitz model is approximately 6 times higher than the relevant return generated by individual stock.

\subsection{Efficient Frontier of Maximized Portfolio Return}

Figure 3 demonstrates a set of portfolios offering the highest rate of return for a given certain degree of standard deviation. They are the best possible risk-return combinations because with the same level of risk, there are no other portfolios that can provide higher return than the ones located on the efficient frontier. After having the efficient frontier, investors identify the optimal portfolio allocation that best fits their personal risk preference.

\subsection{Maximum Sharpe Ratio Portfolio}

Precise weights for component stocks in the maximum Sharpe ratio portfolio are obtained using the definition (7) of Sharpe's measure, the definition (6) of Markowitz model and equations (3), (4) and (5). They are shown in Table 5.

In the maximum Sharpe ratio portfolio, 35 assets in the sample of 50 stocks remained with different weight allocation. The rest 15 out of 50 stocks are 


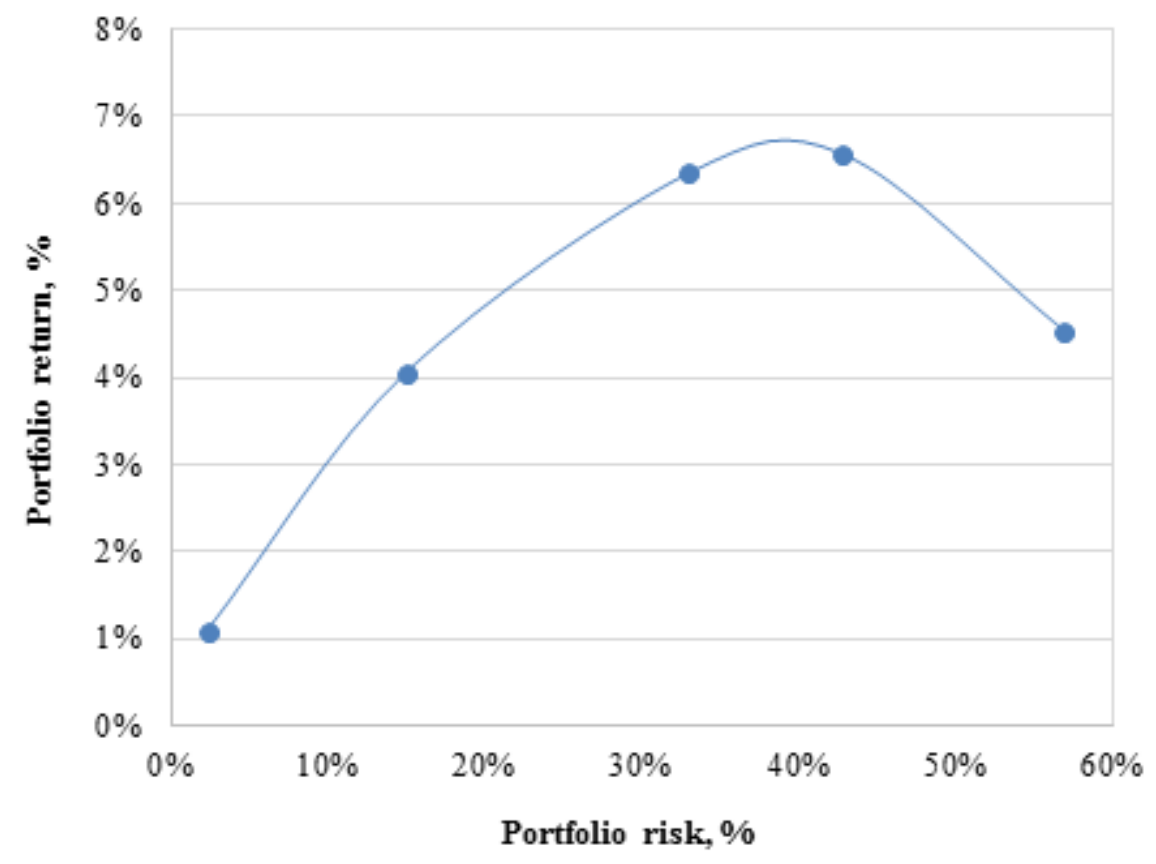

Figure 3: Efficient frontier maximizing portfolio return

excluded. It is noteworthy that 0SP and CENHL are the impressive stocks receiving the largest weight allocation of $12,17 \%$ and $9,64 \%$, respectively. This portfolio has its expected return of $0,73 \%$ with the level of risk of $1,34 \%$ per week and Sharpe ratio 0,43 with an amount of risk-free assets equal to $0,16 \%$.

\subsection{Efficient Frontier of Maximized Sharpe Ratio Portfolio}

Figure 4 demonstrates a set of portfolios offering the highest Sharpe ratio portfolio for any target rate of risk. Once the efficient frontier is constructed, the task of particular investors is to choose their own applicable portfolio from points on the graph depending on their distinguished risk preference. 
Table 5: Maximum Sharpe ratio portfolio.

\begin{tabular}{llllll}
\hline Name & $\omega_{i}, \%$ & Name & $\omega_{i}, \%$ & Name & $\omega_{i}, \%$ \\
\hline ZHBG & 0,52 & HES & 7,28 & ZAHZA & 1,36 \\
BIOV & 2,00 & AGR & 7,68 & LAVEN & 1,17 \\
HVAR & 2,90 & MCH & 7,15 & AROMA & 0,87 \\
MONBAT & 2,40 & BREF & 2,08 & ROZA & 3,03 \\
ELHIM & 2,28 & DOVUHL & 0,96 & ELTOS & 1,48 \\
E4AP & 0,53 & 3CZ & 2,63 & TODOROF & 0,93 \\
ALUM & 5,71 & HNVEK & 2,09 & GAGBT & 1,55 \\
CENHL & 9,64 & MOMKR & 0,62 & OEA & 3,09 \\
LAND & 1,38 & ERH & 0,56 & FEEI & 0,76 \\
FZLES & 3,77 & ODES & 4,20 & ERGC3 & 1,30 \\
FPP & 2,35 & BRP & 1,23 & UPAC & 1,20 \\
0SP & 12,17 & KRS & 1,13 & & \\
\hline \multicolumn{5}{l}{ Portfolio return } & \multicolumn{5}{c}{$0,73 \%$} \\
Portfolio risk & \multicolumn{5}{c}{$0,34 \%$} \\
Sharpe ratio
\end{tabular}

\section{Conclusion}

The study achieved its target of the practical application of Markowitz model to set up an optimal portfolio included stocks traded in Bulgarian stock market during the period from January 2013 to December 2016. It was figured out that during the study time period the efficient portfolios formed by Markowitz model did perform better than any domestic individual security. By investing in efficient portfolios - the ones located on the efficient frontier, investors afford to get maximum return on investment given a certain level of risk, maximum Sharpe ratio, or a minimum risk. It is the power of Markowitz diversification by seriously taking into account covariance and correlation between assets. Accordingly, Bulgarian investors, if knowing how to properly apply Markowitz model, certainly can improve their investment performance. 


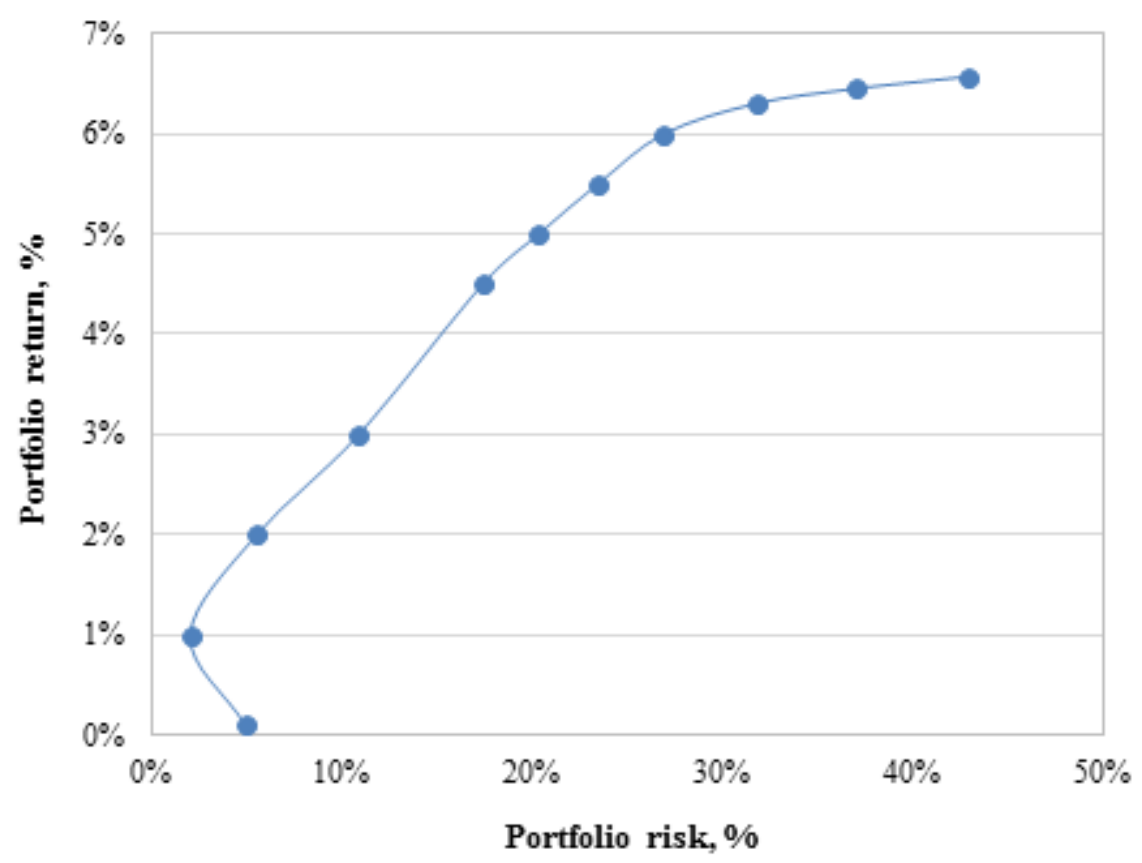

Figure 4: Efficient frontier maximizing Sharpe ratio portfolio

\section{References}

[1] J. Campbell, A. Lo, C. MacKinlay, The Econometrics of Financial Markets, Princeton University Press (1997).

[2] G. Chacko, L. Viceira, Dynamic Consumption and Portfolio Choice with Stochastic Volatility in Incomplete Markets, Review of Financial Studies, 18 (2005), 1369-1402.

[3] W.-P. Chen, H. Chung, K.-Y. Ho, T.-L. Hsu, Portfolio optimization models and meanvariance spanning tests, In: Handbook of Quantitative Finance and Risk Management, Cheng-Few Lee, Alice C. Lee, John Lee, eds., Springer (2010), 165-184.

[4] L.J. Gitman, M.D. Joehnk, Fundamentals of Investing, 3rd ed., Harper \& Row, New York (1988).

[5] R.A. Haugen, N.L. Baker, Dedicated stock portfolios, Journal of Portfolio Management, 16 (1990), 17-22.

[6] H. Konno, A. Suzuki, A mean variance skewness optimization model, Journal of the Operations Research Society of Japan, 38 (1995), 173-187.

[7] H. Konno, H. Yamazaki, Mean-absolute deviation portfolio optimization model and its application to Tokyo Stock Exchage, Managenemt Sci., 37 (1991), 519-531. 
[8] R. Mansini, W. Ogryczak, M.G. Speranza, Conditional value at risk and related linear programming models for portfolio optimization, Annals of Operations Research, 152 (2007), 227-256.

[9] R. Mansini, W. Ogryczak, M.G. Speranza, Portfolio optimization and transaction costs. In Quantitative financial risk management: Theory and practice, Oxford: Wiley (2015), 212-241.

[10] R. Mansini, W. Ogryczak, M.G. Speranza, Twenty years of linear programming based portfolio optimization, Europian Journal of Operational Research, 234 (2014), 518-535.

[11] R. Mansini, M.G. Speranza, Heuristic algorithms for the portfolio selection problem with minimum transaction lots, European Journal of Operational Research, 114 (1999), 219233.

[12] H.M. Markowitz, Portfolio Selection: Efficient Diversification of Investments, John Wiley, New York (1959).

[13] H.M. Markowitz, Portfolio selection, The Journal of Finance, 7 (1952), 77-91.

[14] H.M.Markowitz, Mean-Variance Analysis in Portfolio Choice and Capital Markets, Basil Blackwell (1990).

[15] W. Ogryczak, T. Śliwiński, On dual approaches to efficient optimization of LP computable risk measure for portfolio selection, Asia-Pacific Journal of Operational Research, 28 (2011a), 41-63.

[16] W. Ogryczak, T. Śliwiński, On solving the dual for portfolio selection by optimizing conditional value at tisk, Computational Optimization and Applications, 50 (2011b), 591-595.

[17] G. Pogue, An extension ot the Markowitz portfolio selection model to include variable transaction cost, short sales, leverage policies and taxes, Journal of Finance, 25 (1970), 1005-1027.

[18] R. Rockafellar, S. Uryasev, Optimization of conditional value-at-risk, Journal of Risk, 2 (2000), 21-41.

[19] R. Rockafellar, S. Uryasev, M. Zabarankin, Generalized deviations in risk analysis, Finance and Stochastics, 10 (2006), 51-74.

[20] D. Roman, K. Darby-Dowman, G. Mitra, Mean-risk models using two risk measures: A multi-objective approach, Quantitative Finance, 7 (2007), 443-458.

[21] H. Scholz, Refinements to the Sharpe ratio: Comparing alternatives for bear markets, Journal of Asset Management, 7 (2007), 347-357.

[22] W. Shadwick, C. Keating, A universal performance measure, Journal of Portfolio Measurement, 6 (2002), 59-84.

[23] W.F. Sharpe, A Linear Programming Algorithm for Mutual Fund Portfolio Selection, Management Science, 13 (1967), 499-510.

[24] W.F. Sharpe, Capital asset prices: A theory of market equilibrium under conditions of risk, Journal of Finance, 19 (1964), 425-442.

[25] W.F. Sharpe, Mutual fund performance, Journal of Business, 39 (1966), 119-138.

[26] J. Tobin, The theory of portfolio selection in the theory of interest rates, Macmillan: F.H. Hahn and F.P.R. Brechling, London (1965). 
[27] J. Tobin, Life Cycle Saving and Balanced Growth, In: Ten Economic Studies in the Tradition of Irving Fisher, New York: Wiley (1967), 231-256.

[28] P. Xidonas, G. Mavrotas, J. Psarras, Portfolio construction on the Athens Stock Exchange: A multiobjective optimization approach, Optimization, 59 (2010), 1211-1229.

[29] A. Yoshimoto, The mean-variance approach to portfolio optimization subject to transaction costs, Journal of the Operations Research Society of Japan, 39 (1996), 99-117. 
